\title{
Adrenal crisis in metastatic adrenal cortical carcinoma in an infant with neurofibromatosis type 1
}

\author{
*Udeni Anuruddhika Kollurage ${ }^{1}$, R V Samitha Jayawikrama ${ }^{2}$, A D K S N Yasawardana ${ }^{3}$, Navoda \\ Atapattu $^{4}$
}

Sri Lanka Journal of Child Health, 2019: 48(1): 74-76

DOI: http://dx.doi.org/10.4038/sljch.v48i1.8657

(Key words: Neurofibromatosis type 1, adrenal cortical carcinoma (ACC), sub-clinical hypercortisolism, adrenal crisis)

\section{Introduction}

Neurofibromatosis type 1 (NF-1) is associated with a high risk of benign and malignant neoplasms, especially related to the nervous system and endocrine organs, although there is no definite association with adrenal cortical carcinoma $(\mathrm{ACC})^{1}$. Similarly, ACCs are very rare malignancies which may occur at any age but are commoner among children less than 5 years old and adults over 40 years of age and two thirds of them are capable of secreting an excess of corticosteroid hormones ${ }^{1,2,3}$.

\section{Case report}

A five month old baby boy was born to nonconsanguineous healthy parents as the fourth child. He had numerous café au lait patches, which were noted from birth and multiple neurofibromas that were of recent onset. Hence a diagnosis of NF-1 was made. An ultrasound scan of the abdomen at 3 months of age did not show any intra-abdominal or retroperitoneal masses. He was admitted to the Lady Ridgeway Hospital for Children, Colombo, at 5 months of age for fibro-optic laryngoscopy for further evaluation of congenital stridor. During this admission, he underwent general anaesthesia (GA) during which he had a cardiorespiratory arrest which was resuscitated successfully, and he was transferred to the intensive care unit (ICU). The investigations done during the resuscitation revealed severe hyperkalaemia, hyponatraemia and hypoglycaemia. During the ICU stay he had repeated episodes of cardiorespiratory depressions and arrests, which were always associated with hyperkalaemia, hyponatraemia and hypoglycaemia. His venous blood gas, capillary blood sugar and serum electrolyte reports are shown in Table 1.

Table 1: Venous blood gas capillary blood sugar and serum electrolyte reports of the 5 month old baby

\begin{tabular}{|c|c|c|c|c|}
\hline Investigation & $\begin{array}{c}\text { 22/12/2016 } \\
9.00 \mathrm{am}\end{array}$ & $\begin{array}{c}22 / 12 / 2016 \\
2.00 p m\end{array}$ & $\begin{array}{c}23 / 12 / 2016 \\
1.13 p m\end{array}$ & $\begin{array}{c}23 / 12 / 2016 \\
3.40 p m\end{array}$ \\
\hline $\mathrm{pH}$ & 7.103 & 7.08 & 7.58 & 7.40 \\
\hline $\mathrm{pCO} 2(\mathrm{~mm} \mathrm{Hg})$ & 85.4 & 71.0 & 15.4 & 33.8 \\
\hline $\mathrm{pO} 2(\mathrm{~mm} \mathrm{Hg})$ & 20.2 & 23.3 & 120.2 & 91.3 \\
\hline Bicarbonate (mmol/L) & 27.0 & 21.0 & 14.4 & 21.2 \\
\hline Base excess & -2.8 & -3.7 & -7.8 & -3.8 \\
\hline Capillary blood sugar (mg/dl) & 42 & 41 & 37 & 63 \\
\hline Sodium $(\mathrm{mmol} / \mathrm{L})$ & 121.8 & 129.4 & 122.4 & 132.0 \\
\hline Potassium (mmol/L) & 19.74 & 12.15 & 9.13 & 3.99 \\
\hline \multicolumn{2}{|c|}{$\begin{array}{l}{ }^{1} \text { Senior Registrar in Paediatric Endocrinology } \\
{ }^{2} \text { Consultant Anaesthetist, }{ }^{3} \text { Consultant ENT } \\
\text { Surgeon, }{ }^{4} \text { Consultant Paediatric Endocrinologist } \\
\text { Lady Ridgeway Hospital for Children, Colombo } \\
\text { Sri Lanka } \\
{ }^{*} \text { Correspondence: udenikollurage@yahoo.com }\end{array}$} & \multicolumn{3}{|c|}{$\begin{array}{l}\text { Despite treatment with hydrocortisone and } \\
\text { fludrocortisones, his condition deteriorated and he } \\
\text { needed inotropic support. In spite of repeated fluid } \\
\text { boluses and regular doses of glucocorticoids and } \\
\text { mineralocorticoid, baby progressed to circulatory } \\
\text { failure and succumbed within two days of the } \\
\text { initial cardiorespiratory arrest. }\end{array}$} \\
\hline
\end{tabular}

(Received on 30 March 2017: Accepted after revision on 19 May 2017)

The authors declare that there are no conflicts of interest

Personal funding was used for the project.

Open Access Article published under the Creative

Commons Attribution CC-BY (c) (P)
The computed tomography (CT) scan of abdomen revealed a poorly enhancing hypodense mass, measuring $3.1 \mathrm{~cm}$ (antero-posterior), $4.3 \mathrm{~cm}$ (cephalo-caudal) and $3.4 \mathrm{~cm}$ (transverse) in size, in the region of left adrenal gland, with no separately identifiable left adrenal gland. There were numerous focal lesions involving all segments of the liver, suggestive of liver metastases (Figure 1). 

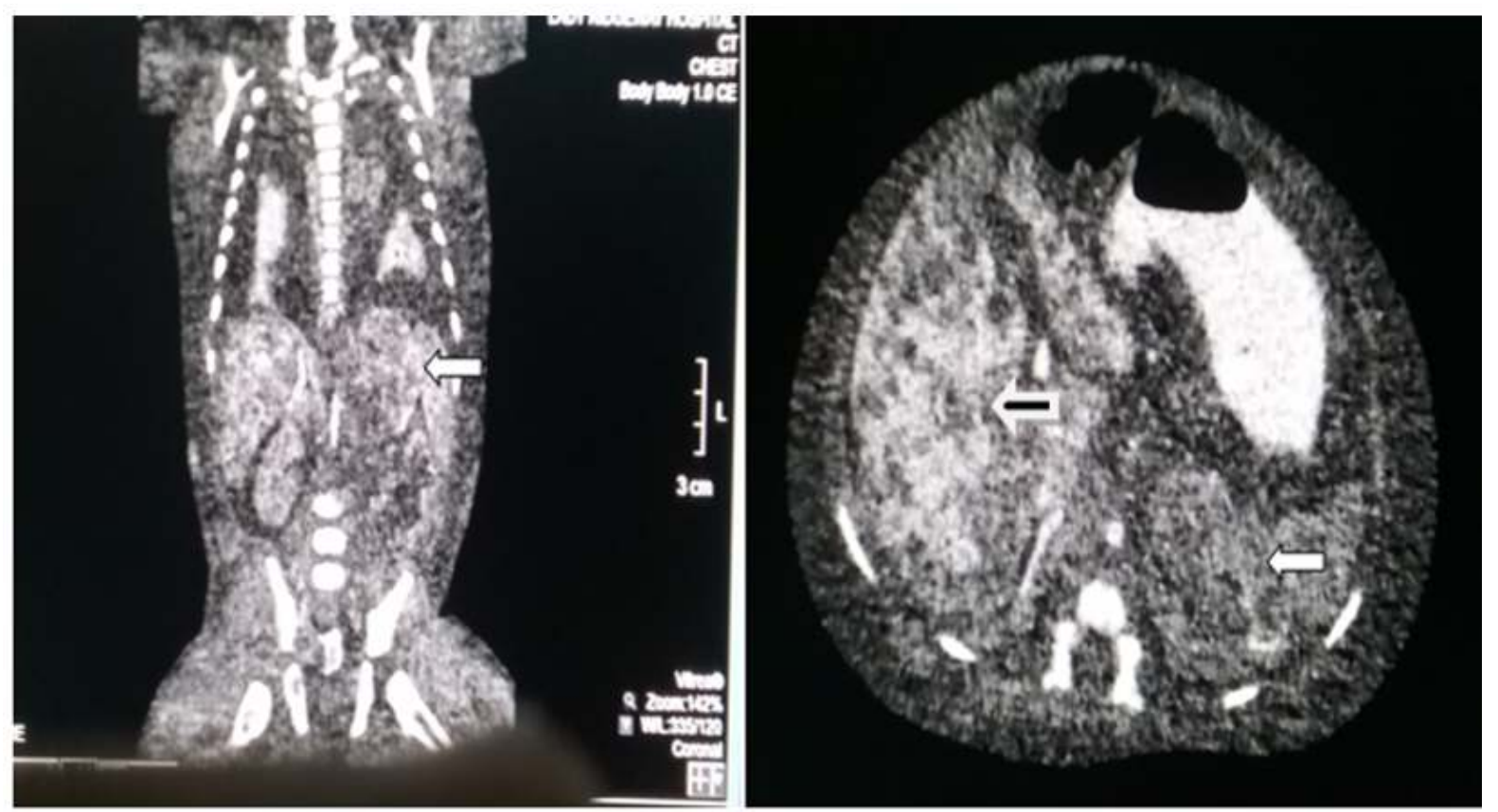

Figure 1: Computed tomography scan of abdomen with adrenal carcinoma and liver metastasis

- Liver metastasis

\section{Discussion}

NF-1 is an autosomal dominant disease, inherited due to loss of function mutation in NF-1 gene, in chromosome $17 \mathrm{q} 11.2$, with the prevalence of 1 : 3000 live births ${ }^{4}$. Clinical diagnosis of NF-1 was considered with the presence of multiple neurofibromas and more than six café au lait patches more than $5 \mathrm{~mm}$ in size. NF-1 is associated with high risk of benign and malignant neoplasms, especially in nervous system, skin, gastrointestinal system stroma cells, lungs, muscles and phaeochromocytoma ${ }^{1,4,5,7}$. On the other hand, thyroid nodules, parathyroid adenomas, carcinoid tumors are also reported ${ }^{7}$. There are cases of ACCs reported in patients with NF-1 in the medical literature. Child with ACC and systemic metastasis has been described ${ }^{6}$. Definite association between these two conditions is still not established ${ }^{2-5}$.

ACCs are very rare malignant tumours which may occur at any age. They are commoner among children less than 5 years old and adults over 40 years of age ${ }^{1,3}$. Ten to fifteen percent of ACCs are inherited with a mutated gene, such as Li Fraumeni syndrome, Lynch syndrome and multiple endocrine neoplasia type 1 (MEN1) but there is no evidence to suggest an association between NF-1 and $\mathrm{ACCs}^{2,3,5}$. Two thirds of ACCs are capable of secreting excess hormones which can result in malignant hypertension, Cushing disease and virilization $^{1}$.

This patient presented with adrenal crisis but did not reveal clinical features of long standing corticosteroid excess. In addition, ultrasound scan of abdomen was done at 3 months of age which did not reveal any intra-abdominal or retroperitoneal masses. ACCs are generally fast growing malignancies, detected at late stages ${ }^{9}$. Treatment depends on the tumour spread, general wellbeing and fitness of the patients for combined surgery, chemotherapy and radiotherapy 9 .

Hypersecretion of adrenal cortisol, which is called 'adrenal hypercortisolism', can have wide variability in the degree of hyper secretion as well as in the degree of clinical manifestations ${ }^{9,10}$. The presentation can vary from sub-clinical hypercortisolism to full blown Cushing syndrome ${ }^{7,10}$. Patients who had undergone unilateral adrenalectomy for subclinical hypercortisolism had progressed to adrenal insufficiency after surgery, ${ }^{9}$. This can be explained theoretically, as hypercortisolism of the diseased adrenal gland has suppressed the normally functioning contra-lateral adrenal gland and child later presented with adrenal crisis when the diseased gland and the hypercortisolism were absent after surgical removal ${ }^{7-10}$. The patient had adrenal crisis due to the same reason where the contralateral adrenal gland had been suppressed due to tumour in the left adrenal gland. When the gland had bleeding and necrosis, the contralateral suppressed adrenal gland was not able to produce stress hormones resulting in adrenal crisis. There is no biochemical evidence for cortisol excess, as this infant did not survive through the disease process and was not stable enough for the investigations during the presentation. 
ACC is a rare association in NF-1 and unilateral ACC can present with adrenal crisis, due to suppression of contralateral non affected adrenal gland with sub-clinical hypercortisolism of the affected gland.

\section{References}

1. Menon RK, Ferrau F, Kurzawinsk TR, Rumsby G, Freeman A, Amin Z, et al. Adrenal cancer in neurofibromatosis type 1: case report and DNA analysis: Endocrinology, Diabetes \& Metabolism Case Reports 2014; 2014: 140074.

2. Gundgurthi A, Kharb S, Dutta MK, Garg MK, Khare A, Jacob MA et al. Childhood adrenocortical carcinoma: Case report and review. Indian Journal of Endocrinology and Metabolism 2012; 16(3): 431-5.

https://doi.org/10.4103/2230-8210.95699

PMid: 22629514 PMCid: PMC3354855

3. Lalli E, Figueiredo BC. Pediatric adrenocortical tumors: what they can tell us on adrenal development and comparison with adult adrenal tumours. Frontiers in Endocrinology 2015; 6:23.

https://doi.org/10.3389/fendo.2015.00023

PMid: 25741319 PMCid: PMC4332354

4. Kistler AC. Malignancies in patients with neurofibromatosis type 1 (NF-1). Cancer Therapy Advisor 2014. Available from: http://www.cancertherapyadvisor.com/generaloncology/malignancies-in-patients-withneurofibromatosis-type-1-nf-1/article/371756/

5. Korf BR. Malignancy in neurofibromatosis type 1: The oncologist 2000; 5(6): 477-85. https://doi.org/10.1634/theoncologist.5-6-477 PMid: 11110599

6. Wagner AS, Fleitz JM, KleinschmidtDemasters BK. Paediatric adrenal cortical carcinoma: brain metastases and relationship to NF-1, case reports and review of the literature. Journal of Neuro-oncology 2005; 75(2):127-33.

https://doi.org/10.1007/s11060-005-0376-Z

PMid: 16132517
7. Dalmazi GD, Berr CM, Fassnacht $\mathrm{M}$, Beuschlein F, Reincke M. Adrenal function after adrenalectomy for subclinical hypercortisolism and Cushing's syndrome: A systematic review of the literature. Journal of Clinical Endocrinology and Metabolism 2014; 99(8):2637-45.

https://doi.org/10.1210/jc.2014-1401

PMid: 24878052

8. Lodish MB, Stratakis A. Endocrine tumours in neurofibromatosis type 1 , tuberous sclerosis and related syndromes. Best Practice \& Research Clinical Endocrinology and Metabolism 2010; 24(3): 439-49. https://doi.org/10.1016/j.beem.2010.02.002 PMid: 20833335 PMCid: PMC2939061

9. Kulshreshtha B, Arora A, Aggarwal A, Bhardwaj M. Prolonged adrenal insufficiency after unilateral adrenalectomy for Cushing's Syndrome: Indian Journal of Endocrinology and Metabolism 2015; ;19(3): 430-2.

https://doi.org/10.4103/2230-8210.152794

PMid: 25932404 PMCid: PMC4366787

10. Serter R, Koç G, Demirbas B, Çulha C, Öngören AU, Üstün H, Aral Y. Acute adrenal crisis together with unilateral adrenal mass caused by isolated tuberculosis of adrenal gland. Endocrine Practice 2003; 9(2):157-6 https://doi.org/10.4158/EP.9.2.157

PMid: 12917080 